\title{
A NOÇÃo dE DESTINO NA ASTROLOGIA E SUA INFLUÊNCIA NO PENSAMENTO OCIDENTAL: NOTAS INSPIRADAS EM UMA LEITURA CRÍTICA DE THE STARS DOWN TO EARTH - T.W.ADORNO
}

\author{
The Notion of FAte in Astrology and ITS INFLUENCE ON WEStERN THOUght:
} NOTES INSPIRED BY A CRITICAL READING OF THE STARS DOWN TO EARTH - T. W. ADORNO

VANI TEREZINHA DE REZENDE ${ }^{(*)}$

\begin{abstract}
RESUMO
Tomando como referência a crítica feita por T.W. Adorno, em sua obra The Stars down to Earth, à astrologia, caracterizada por ele como mera superstição, este artigo propõe-se a mostrar que, ao contrário dessa desqualificação, existe um sistema astrológico de conhecimento que traz em seu âmago noções profundamente enraizadas em outros sistemas de representação da realidade - políticos, religiosos, mágicos, entre outros. Uma dessas noções é a de Destino, que encontra na astrologia seu lugar privilegiado e é objeto de reflexão deste estudo. Por meio de alguns registros históricos sobre essa noção pretende-se tentar uma outra via de compreensão de um pensamento muito antigo, que influenciou durante muitos séculos a ciência e a filosofia e continua influenciando diferentes formas de pensamento. Para isso dialoga principalmente com o pensamento dos estóicos, de Santo Agostinho, Boécio, Marcílio Ficino e resgata um debate sobre a nossa representação do mundo científica-positivista.
\end{abstract}

Palavras-Chave: Destino. Astrologia. Sistema de Conhecimento. Crítica. Superstição.

\section{ABSTRACT}

Taking as reference the criticism made by T.W.Adorno, in his work The Stars down to Earth, to the astrology, characterized by him as mere superstition, this article aims to show that, contrary to this disqualification, there is an astrological system of knowledge which brings notions that are deeply rooted in other systems of reality representation - political, religious, magical, among others. One of these notions is the Fate [Destiny], which has a privileged place in astrology and is the subject of this study. Through some historical records on this notion we intend to try another way of understanding a very old thought which influenced many centuries science and philosophy and continues to influence different ways of thinking. To this purpose, it dialogues mainly with the thought of the Stoics, of Augustine, Boethius, Marsilius Ficino and rescues a debate about our representation of scientific-positivist world.

KEYWORDS: Fate. Astrology. Knowledge System. Criticism. Superstition.

\footnotetext{
(*) Doutora em Filosofia pela Universidade se São Paulo. Professora de Filosofia. Atualmente desenvolve pesquisa na área de Filosofia da Religião e em religiosidade pós-moderna. Integra o Grupo de Pesquisa Teoria Crítica e Filosofia Social da Universidade Federal de Uberlândia. Tem experiência na área editorial, atuando em publicações científicas como editora responsável e na edição e preparação de textos, redação e revisão. Foi responsável pela criação do Setor de Publicações Científicas da Faculdade Católica de Uberlândia, onde deu aulas de Filosofia (2004-2012). Membro do Conselho Editorial de várias revistas científicas.

${ }^{1}$ Texto adaptado e ampliado de um capítulo de minha tese de doutorado, Luzes e Estrelas: Adorno e a astrologia, defendida em 2003 pelo Programa de Pós-Graduação em Filosofia da Universidade de São Paulo, sob a orientação da profa Olgária C. F. Matos, e publicada pela Associação Editorial Humanitas/FAPESP, em 2006.
} 


\section{INTRODUÇÃO}

A postura de dirigir o olhar não para o que se considera "científico" do ponto de vista atual, mas para tudo o que em alguma época foi proposto como científico, não exige que se faça a defesa da astrologia. Esta exposição não tem a pretensão de fazer uma avaliação de um pensamento muito antigo, mas apenas de levantar alguns registros de como ele se apresenta em alguns momentos da história. Tomar-se-á como fio condutor a noção de Destino, dando prosseguimento ao que Alexandre Koiré diz em seu Místicos, Espirituais e Alquimistas do século XVI alemão:

Quando se aborda o estudo de um pensamento que não é o nosso, o mais difícil e o mais necessário - é [...] não tanto captar o que não se sabe e o que sabia o pensador em questão, quanto esquecer o que sabemos e o que cremos saber. [...] Às vezes é necessário não só esquecer verdades que se converteram em partes integrantes do nosso pensamento, como até mesmo, inclusive, adotar certos modos, certas categorias de raciocínio, ou ao menos certos princípios metafísicos, que para as pessoas de uma época pretérita eram bases de raciocínio e de busca tão válidas e também tão seguras como são para nós os princípios da física matemática e os dados da astronomia. (p. 71)

Ao contrário dessa perspectiva, T. W. Adorno, em sua obra The Stars Down to Earth (1975, p. 17-18), defende que a distinção efetuada entre alquimia e química, astrologia e astronomia torna inconcebível pensar ainda hoje numa superstição como a astrologia. Será que as coisas são realmente assim?

A razão em Adorno é pensada dentro do paradigma indivíduo-liberdade e referida à totalidade social. Dessa maneira, fica embargada qualquer outra forma de pensar que não seja aquela que privilegia o indivíduo, que só pode se tornar um sujeito livre e crítico quando usa a razão para refletir sobre a totalidade social. Será que nenhuma outra leitura da vida social que pense o homem como parte de uma totalidade mais ampla abre espaço para que ele possa afirmar sua liberdade e ser indivíduo? Onde se pode olhar com desconfiança para Adorno é nessa impossibilidade de pensar além que seu pensamento instaura.

De outra parte, por mais que se entenda o enfoque crítico de Adorno em relação à cultura de massa (jazz, música popular, novela de rádio, horóscopo etc), analisada em suas analogias com o antissemitismo, no contexto histórico do nazismo, não é excludente pensar a astrologia para além de um ponto de vista que a enxerga apenas como indústria cultural. Por ser um "sistema de 
conhecimento" muito antigo, ela pode ser abordada ao lado de outros sistemas de representação da realidade, como se verá a seguir. ${ }^{2}$

No horizonte da história do conhecimento pode-se observar que há diversas formas de pensamento político, religioso, mágico e outros que procuram refletir sobre questões intimamente ligadas à astrologia. Como, por exemplo, aquelas que se relacionam à natureza e suas leis, ao sentido e lugar que o homem ocupa no universo, à relação homem-cosmos, enfim, ao modo como o homem se comporta diante de um conjunto de forças que, em princípio, não são determinadas por ele. Entre estas podem ser vistas as que se encontram na origem dos grandes problemas humanos, como os que se expressam nos pares de opostos liberdade-necessidade, determinismo-livre-arbítrio, que constituem também o cerne das preocupações de Adorno. Uma noção chave que percorre todos esses sistemas de conhecimento é a de Destino, à qual se relacionam outros termos de suma importância para a história do pensamento ocidental, como Sorte, Acaso, Fortuna, Fatum, Fatalidade, Predestinação, Lei Natural, Providência Divina. Para melhor compreensão desse tema, expor-se-á a seguir um breve panorama da extensão histórica das questões e respostas que são dadas a essa interrogação milenar do ser humano.

No que diz respeito a uma abordagem propriamente histórica, que não é objeto deste estudo, deve-se observar que, no caso da astrologia, quando se lida com sua história, depara-se antes de tudo com o problema da literatura sobre o assunto. Quase não se encontra literatura boa disponível a respeito. Se o historiador é astrólogo, ele faz uma revelação gradativa do que considera ser a verdade, sem adotar o mínimo procedimento científico na abordagem do tema. Como o esforço de pesquisa para abarcar 3000 anos ou mais de história teria que ser imenso, é preciso pegar um ponto específico.

Esse é o caso, por exemplo, da tese de doutorado de Juliana Mesquita Hidalgo Ferreira (2005), intitulada As influências celestes e a Revolução Científica: a astrologia em debate na Inglaterra do século XVII. O retrato do problema documental encontra-se bem explicado na referência que faz do livro de S. Jim Tester, A history of western astrology, onde se fala de três categorias de livros sobre o assunto: "primeiro os de astrólogos ou simpatizantes, que são úteis para explicar como a astrologia funciona” [...], mas que são não-históricos

\footnotetext{
2 Essa abordagem com certeza não seria estranha a Adorno, que diz explicitamente não pretender "decifrar o ocultismo" (The Stars, p. 19), ao qual pertence a astrologia, delimitando dessa forma seu objeto de estudo. De qualquer forma permanece o problema de reduzir a astrologia a uma superstição
} 
e acríticos. "Em segundo lugar existem os que atacam a astrologia" [...]: os do passado são úteis como fontes de informação, mas são tão acríticos e nãohistóricos como os primeiros. Em terceiro lugar vêm as histórias ou delineamentos populares que aumentam em número e não em qualidade. (FERREIRA, 2005, p. 365). Após colocar a questão histórica da própria astrologia, a autora procura resgatar um período importante, o século XVII, para a compreensão da função social e cultural que a astrologia exerce e que não se reduz a uma superstição. Alguns questionamentos a esse respeito são tratados na conclusão deste artigo.

\section{Astrologia: Destino, Moira E ProvidênCIA}

Desde os tempos chamados míticos, a preocupação com o destino sempre esteve associada ao cosmo ordenado, interligado e, por extensão, à astrologia. A partir das primeiras cosmogonias e teogonias e da visão cosmológica desponta, na Grécia arcaica, o conceito de Moira, que se tornará presente em todo o mundo grego, como "porção", "sorte" que cabe a cada um. Pela função da Moira nenhum indivíduo se constituía sem que a Totalidade Cósmica estivesse constituída em todas as suas partes. O duplo aspecto da Moira encontra-se já em Hesíodo: as Moiras são filhas da Noite e são filhas da união de Zeus e Thémis. ${ }^{3}$ No seu aspecto de Necessidade, as Moiras eram a encarnação de uma lei inexorável, à qual até os deuses estavam sujeitos, como é expresso em Ésquilo no seu Prometeu Prisioneiro (1985, 515, p. 47):

Coro: Quem então da Necessidade é o timoneiro?

Prometeu: Moiras triformes e memoriosas Eríneas.

Coro: E mais fraco que essas é Zeus?

Prometeu: Não escaparia ao já dado destino.

Mas a astrologia não nasceu na Grécia. Sua história oficial mostra-a ligada originalmente aos progressos na observação da regularidade do movimento dos astros e à observância de ritos mágico-religiosos: astrologia e astronomia, ciência e magia não se dissociam. A "ciência” dos astros aparece em várias civilizações : na Caldéia, na Índia, na China, na América Latina. "Sua prática no Ocidente origina-se em um antigo corpo de conhecimentos iniciado pelos

\footnotetext{
3 Jaa Torrano explica que com essa dupla origem elas são, de um lado, o limite positivo e configurativo de cada ser humano ou divino, e, de outro, o limite negativo, coercitivo. Afirmam tudo o que um ser é e pode ser e negam tudo o que um ser não é e não pode ser. Enquanto é o próprio ser de cada ser, é também para cada ser todas as coerções que pode padecer, ou seja, o que provém de tudo o que lhe é exterior e Outro. Neste lote, porção que cabe a cada um , coincidem afirmação e negação, liberdade e necessidade, espontaneidade e coerção, ipseidade e alteridade. (Ver HESÍODO. Teogonia, A origem dos Deuses. Estudo e tradução de Jaa Torrano. São Paulo, Massao Ohno - Roswitha Kempf Editores, 1981, p. 97-98.)
} 
babilônios, desenvolvido pelos gregos e romanos e ampliado pelos árabes no início da Idade Média”, observa Keith Thomas (1991, p. 237).

No helenismo, uma concepção de mundo religiosa se desenvolvia por toda parte sob o signo da deusa Fortuna (Túkhé) e do fatalismo astral. Nessa época, a magia e a astrologia se popularizavam e atraíam certos filósofos, como os estóicos, que reconheciam a validade da astrologia. (Eliade, 1979, T.II, V. 2, p. 130). De imediato, a idéia de Fatalidade nos remete às noções estóicas de Heimarmenê (destino, lei necessária que rege as coisas) e Ekpyrosis (conflagração universal que ocorre quando os astros voltam a uma mesma posição do início, ocasionando uma destruição). $O$ aspecto fatalista da concepção do destino, tal como a concebem os estóicos, se expressa sobremaneira na sua teoria da Ekpyrosis:

Os estóicos dizem que quando os planetas voltam ao mesmo signo, seja quanto à longitude seja quanto à latitude em que cada um estava no princípio, quando o universo se constituiu na origem, nesses períodos de tempo advém uma conflagração e uma destruição dos seres; e novamente o cosmo se refaz do princípio; e de novo, movendo-se os astros no mesmo modo, cada evento acontecido no precedente período outra vez se realiza, invariavelmente.

(NEMÉSIO, apud REALI, 1994. V. III).

Se, por um lado, os estóicos davam um novo sentido ao destino determinado pelos astros, por outro, não se pode ignorar o fato de que, graças aos cálculos efetuados pelos babilônios, a leitura do mundo incluía sua divisão em períodos e crises dominados pelos planetas. Essa doutrina, segundo a qual tudo o que existe possui uma duração determinada pelos astros, bem como a técnica astrológica que a aplica desenvolvem-se a partir dos estudos dos babilônios sobre as revoluções astrais. Só que, com os estóicos, o homem descobre-se não apenas solidário, mas também determinado pelo ritmo dos astros.

A palavra Heimarmenê (destino) deriva do particípio passado de verbo meiromai (ter parte, ter por sorte), cuja raiz mer encontra-se em meros ( parte) e possivelmente em Moirai (As Moiras, as Eríneas, as Parcas). Na filosofia estóica, contudo, não tem a mesma carga dramática que se encontra entre os grandes trágicos gregos, onde se mostra como uma força terrível e extramundana que pune os culpados por sua falta. Com o estoicismo, o destino é uma realidade natural, aparecendo como um nexus causarum, uma disposição imutável, cada coisa acompanhando cada outra de maneira inviolável na ordem do todo. É a "razão do mundo, ou a lei de todas as coisas do mundo regidas e governadas pela providência, ou a razão pela qual as coisas passadas foram, as 
presentes são e as futuras serão." (Plutarco?)4. Um Logos que é também um sopro vital e divino (pneuma), força que preside à organização de tudo. Do ponto de vista das coisas, essa ordem é Heimarmenê e do ponto de vista de Deus é Pronóia (Providência). "Zenão pensa que a lei natural é divina e que esta força se mantém como é necessário, governando e contendo os contrários.” (CíCERO)5 .

Em seu panteísmo monista, os estoicos identificam Destino, Providência, Razão com Deus, considerado como natureza (cosmos) e como natureza intrínseca operante nas coisas (logos). Dessa forma, Crisipo diz que a adivinhação é "a capacidade de conhecer, de ver e de explicar os sinais com que Deus se manifesta aos homens. O seu papel é o de revelar com antecedência as intenções dos deuses em relação aos homens, de saber como os poderemos satisfazer e tornar favoráveis." (CÍCERO) ${ }^{6}$. A sabedoria humana consiste, pois, em tomar consciência dessa força cósmica (Destino, Providência) que existe em todas as coisas, aceitando a vida do homem, impassivelmente, como parte da ordem do mundo e ligada a ele pela "simpatia universal" que une os seres entre si, indiferente aos males, aspectos isolados do todo. A ordem do mundo, o movimento regular do céu e dos astros mostram que tudo faz parte de um plano rigoroso: não há lugar nessa ordem para a espontaneidade ou o acaso. Mas, pelo fato de cumprir com o seu dever, obedecer à lei da natureza, executando a vontade divina, o sábio prova sua liberdade e transcende o determinismo. Em suma, ao praticar a sabedoria, o homem realiza a identidade com o divino e assume livremente seu destino.

O destino, para os estóicos, não deve ser confundido com a Fortuna. Embora ambos se refiram às ações humanas e ao tempo, é preciso distingui-los. Se no destino a sequência dos acontecimentos é racional e necessária, devendo o sábio agir de acordo com as causas naturais, na Fortuna os acontecimentos são contingentes e produzidos pelo encontro de causas secundárias e fracas que se aproveitam das primárias. "Enquanto querer o destino é a ação própria do homem virtuoso que conhece as causas necessárias de sua ação e das ações da natureza, a Fortuna é o lugar da pura paixão”. (CHAUí, 1999, p. 459).

\footnotetext{
4 PLUTARCO? Des. Op. des. Phil., XXVIII. In: BRUN, Jean. O Estoicismo. Lisboa, Edições 70, 1986, p. 56. 5 CÍCERO, De natura deorum, II, 5. In: BRUN, Jean. O estoicismo. Lisboa: Edições 70, 1986, p. 56. ${ }^{6}$ CÍCERO, De divinatione, II, 63. In: BRUN, Jean. O estoicismo. Lisboa: Edições 70, 1986 p. 61.
} 
A imagem cristalizada da Fortuna mostra-a "representada por uma jovem belíssima, de olhos vendados, que traz numa das mãos o globo e na outra uma cornucópia; tem na cintura um cinto com os signos do zodíaco; vem com um manto agitado pelo vento; tem asas nos pés e pisa sobre a roda que faz girar com os pés." (CHAUí, 1999, p. 460). Essas asas indicam que a fortuna age porque tem a seu favor o tempo - que não é o tempo nem do destino, nem da providência, nem da natureza, mas o tempo efêmero de que se vale: o kairós, o instante oportuno, o momento em que se deve saber agarrar a oportunidade, a iniciativa ética que dobra as paixões. "Graças à liberdade da vontade, graças à racionalidade de sua natureza, o agente virtuoso é aquele que delibera no momento oportuno considerando os efeitos de sua ação, de maneira a não agir sob o impulso sedutor da fortuna que o fará, logo adiante, pagar o preço da imprudência.” (CHAUí, 1999, p. 461).

$\mathrm{Na}$ época helenística, sobretudo durante o Império Romano, paralelamente às novas filosofias da antiguidade clássica - o estoicismo, o epicurismo, o ceticismo e a doutrina dos cínicos -, novas criações religiosas impõem-se em todas as cidades que, após as conquistas de Alexandre, desenvolvem-se sob o signo do sincretismo greco-oriental, ilustrando a poderosa reação espiritual do Oriente vencido. A promessa de salvação constituirá a principal novidade e a característica mais marcante dessas religiões. "Poder-se-ia dizer que as promessas de salvação forcejam por exorcizar o prestígio da deusa Túkhé (a 'Sorte”; latim, Fortuna). Caprichosa e imprevisível, Túkhé traz, indiferentemente, felicidade ou má sorte; manifesta-se como Anánkê (necessidade) ou Heimarménê (destino) [...]” (EliadE, 1979, p. 43), e encontra-se associada ao fatalismo astral.

As respostas que as religiões de salvação procuram dar apoiam-se na convicção de que certos seres divinos são superiores ao Destino. "Nos mistérios de Isis, a deusa assegura ao iniciado que pode prolongar-lhe a vida além do termo fixado pelo destino. Nos Louvores de Isis e Osíres, a deusa proclama: 'Conquistei o Destino e o Destino me obedece'. De mais a mais, Túkhé torna-se atributo de Ísis.” (EliADE, 1979, p. 44). Se antes o próprio Zeus era subjugado pelo Destino, agora, numa nova etapa, Ísis conquista o Destino, impondo-lhe limites. Como os deuses, os iniciados também não serão mais determinados pelo Destino. 


\section{A SOLUÇÃO DO CRISTIANISMO: CISÃO ALMA-CORPO}

Dentro desse contexto cabe perguntar qual seria a solução do cristianismo para o homem que quer sair da alternância da boa ou má sorte. Não será, por certo, a via astrológica. Consta que Santo Agostinho, no século IV, tinha um bom conhecimento dos astros, chegando a ser, quando jovem, um adepto fervoroso da astrologia, antes mesmo da sedução pela cosmologia maniqueísta. Após sua conversão se opôs fervorosamente a ela. Para ele, aparentemente a astrologia negava o livre-arbítrio e poderia levar os homens a se resignarem com o destino em vez de lutarem pela graça. Os astrólogos dispõem de uma arte que lhes permite calcular o curso do tempo no firmamento, mas não têm condição de predizer acontecimentos relativos a decisões e escolhas do homem. A racionalidade da maravilhosa ordem que ele percebe no firmamento é prova da força criadora de Deus e o acaso que observa nos fatos imprevistos está escondido no abismo de seu incorruptível juízo, sendo acessível a cada um segundo os merecimentos ocultos da sua alma. (Confissões, VII, 6, 10). O destino humano, para Agostinho, não é puro acaso: existe na alma humana a penetração de uma racionalidade superior de outra ordem. Se a predição do astrólogo se realiza, deve-se, pois, não à sua arte, mas à "sorte" (sors). (Confissões, VII, 6, 9).

Renato Janine Ribeiro mostra que foi Boécio, filósofo cristão do século VI, quem tornou o tema da Fortuna, constante em suas reflexões, um topos do pensamento ocidental. Na sua Consolação da Filosofia, segunda obra mais lida na Idade Média (depois da Vulgata), Boécio mostra que "a fortuna está associada às tribulações de quem se meteu (como ele), e se alienou, na vita activa" (JANINE, 1993, p. 28). Para se resignar ao desfecho de uma morte cruel, escreveu, na cadeia, a Consolação. "Nesta obra se vai consolidar, em antítese à Fortuna, o papel da Consolatio, que - identificada por Boécio à filosofia tentará aliviar de seu desespero as vítimas da fortuna, ensinando-lhes que uma vida recatada, contemplativa, seria menos infeliz” (p. 28). A solução de Boécio tem como precondição a introdução, trazida pelo cristianismo, de um elemento novo: a serenidade de espírito, que só a fé pode dar, como "uma boa via para se salvar a alma” (p. 29). Assim, não recorrerá à virtude para escapar da fortuna, pois, como esta não incide sobre o merecimento humano, desempenha um papel de "agente indireto da Providência" (p. 29). 
Mais uma vez, podemos notar aqui ecos da influência da idéia de necessidade (Heimarmanê) dos estóicos, com as noções que lhe são inerentes de Destino e Providência, fundamento de todas as elaborações teológicas a partir do neoplatonismo. Embora este defenda a astrologia, Plotino afirma que os astros não exercem influência sobre o plano terrestre, mas apenas anunciam o que a providência decide.

De outra parte, não se pode falar de solução cristã sem retomar Platão. São os ecos da doutrina platônica que se podem ouvir, não só nos primeiros padres da Igreja, como também em Boécio, modelo exemplar de uma concepção do destino que irá perdurar por toda a Idade Média. A cisão platônica entre o mundo sensível e o mundo inteligível, fazendo o poder da Moira recair apenas sobre o mundo sensível, coincide, neste ponto, com a cristã. Tanto para Platão quanto para o cristianismo as tribulações a que Boécio se refere, ligadas à vida ativa e, portanto, ao mundo dos sentidos, constituem o campo específico de atuação da Moira. Sobre a realidade inteligível, ou seja, do espírito, a Moira não tem domínio. O livre-arbítrio só incide no espírito - o corpo está repleto de Destino.

Os estudos realizados por Liz Greene (1995) sobre a Moira procuram trazer à luz o problema da cisão entre corpo e espírito, principalmente quando essa separação se relaciona à maneira essencialmente dualista de lidar com a questão do destino. A mesma cisão encontra-se na noção de Karma do pensamento oriental. A concepção platônica de um mundo sensível, corporal como um reflexo imperfeito do mundo inteligível, aproxima-se da concepção oriental do homem preso ao mundo de maya durante muitas encarnações. "Ele não pode alterar o Karma, mas pode 'diluí-lo' - deixar de se identificar com seu corpo sofredor - e influenciar a predestinação das encarnações futuras, libertando seu espírito, aceitando os golpes do destino com tranquilo desprendimento e centrando-se em sua unidade interior com o divino." (GREENE, 1995, p. 118).

No século XIII, época em que a astrologia é altamente cotada, acreditavase que as distintas partes do corpo humano encontram-se vinculadas de alguma forma ao macrocosmo, de tal modo que os "humores" humanos são determinados pela posição dos corpos celestes. Santo Tomás de Aquino aceita a influência dos astros sobre os efeitos corporais do nosso mundo, mas afirma de maneira peremptória que a vontade do homem não é submetida à necessidade 
dos astros. Ou seja, sobre a realidade inteligível - o espírito, o destino determinado pelos astros não tem domínio.7

\section{MARSILIO FICINO: MAGIA, IMAGINAÇÃO E KAIRÓS}

A ruptura com essa concepção do destino se dará apenas no Quatrocento, com Marsilio Ficino, tradutor, para o latim, do Corpus Hermeticum. Esse foi o primeiro texto grego que Ficino traduziu para o latim, fato que Mircea Eliade considera altamente significativo e que é frequentemente ignorado pelos historiadores. Cosimo Medici comprara o texto e pedira a Ficino que o traduzisse imediatamente, antes das traduções de Platão e Plotino, das quais estava também encarregado. Segundo Eliade, Cosimo e Ficino estavam entusiasmados com a descoberta de uma revelação primordial e não tinham motivo para duvidar de que a egípcia, inspiradora de Pitágoras, Platão e dos Magos Persas, fosse a mais antiga acessível, precedendo a de Moisés. O interesse pelo Egito e o hermetismo, que obsecou, a partir da tradução de Ficino, inúmeros teólogos e filósofos durante quase dois séculos, revela "uma profunda insatisfação em relação à teologia medieval e às concepções medievais do homem e do universo; uma reação contra aquilo a que podemos chamar de cristianismo 'provincial', isto é, puramente ocidental, um anseio por uma religião universalista, trans-histórica, 'mítica'.” (ELIADE, 1989, p. 56)

Designam-se por Corpus Hermeticum os dois livros atribuídos ao lendário Hermes Trimegisto (Três vezes Grande): o Poimandres (Pastor do homem) e o Asclépio (livro iniciático). Os platônicos da Renascença consideravam que estes escritos herméticos fossem remanescentes da biblioteca de Thoth (o Hermes egípcio), contendo a ciência sagrada dos egípcios. Pesquisas contemporâneas, feitas pelo erudito grego Isaac Casaubon, em 1961, situando, com bases filológicas, os textos do Corpus no século II ou III d. C. levam à conclusão de que eles estavam diante não da sabedoria egípcia muito anterior a Platão, mas do "substrato pagão do primitivo cristianismo, aquela religião fortemente tingida de magia e influências orientais, versão gnóstica da filosofia grega e refúgio de fatigados pagãos que buscavam respostas para a vida, diferentes das oferecidas pelos primitivos cristãos”. (YATES, 1995, p. 13-14)

Ainda que as referências dessas obras fossem moldadas num quadro pseudo-egípcio, acabaram por ser consideradas por muitos estudiosos como um

\footnotetext{
7 No que concerne a Tomás e a Astrologia, ver TORRELL, Jean-Pierre OP. Iniciação a Santo Tomás de Aquino : sua pessoa e sua obra. São Paulo: Loyola, 1999, p. 250-251 (comentários sobre a carta de Santo Tomás De Iudiciis astrorum).
} 
repositório de elementos egípcios genuínos. Mircea Eliade completa essas informações de Yates dizendo que essa literatura hermetista com pretensões de ser egípcia baseia-se em conhecimentos do Egito ptolomaico, cuja realidade não deve ser desprezada. (1979, p. 60).

Voltando a Marsilio Ficino, pode-se dizer, com Lyz Greene, que inicialmente ele era mais um filósofo neoplatônico tentando colocar sua mente acima das forças do Destino. Contudo, ao longo de sua vida, sua visão se alterou, principalmente após seu contato com os textos mágicos e alquímicos, não só do Corpus, como de outras obras gregas, filosóficas e astrológicas, que tinham sido enterradas em Constantinopla após o saque de Roma pelos godos. "Por causa dele, também mudou a visão predominante no Renascimento, abrindo aos séculos futuros a possibilidade de o homem ter uma participação ativa no cosmo de Deus e, portanto, fazer uma tentativa válida de estabelecer uma relação diferente com o destino.” (GreEne, 1985, p. 118). Ficino, segundo Liz Greene, deu início, sozinho, à Renascença florentina, ao traduzir Platão para o latim e possibilitar, pela primeira vez desde o início da era cristã, que o Ocidente, impregnado de Aristóteles, tivesse acesso aos textos neoplatônicos. Não importa que o Corpus Hermeticum fosse compilação de obras de vários autores num período de três séculos. "Ficino acreditava em Hermes, e em pouco tempo todo o mundo também acreditava." (GREENE, 1985, p. 119).

No Corpus, além da descrição das doutrinas platônicas, hierarquias astrológicas e de considerações sobre o Destino e a Necessidade, "existe uma declaração de que é possível transformar o destino pela magia”. (GREENE, 1985, p. 119). Ora, essa era uma crença alquímica, e a magia do Corpus é pura alquimia. A Grande Obra realiza-se sobre a essência dos metais, libertada de Moira. Em estreita relação com a astrologia, esse trabalho depende de um acordo com os céus. A teoria alquimista afirma que nem sempre os processos químicos ocorrem sozinhos, mas apenas no momento determinado astrologicamente. Assim, ao trabalhar com a prata, a Lua, planeta relacionado a este metal, precisa estar em uma dada posição, e assim com todos os metais e suas respectivas correspondências aos planetas. A alquimia, portanto, depende de Kairós, que "nessa época e nesse contexto significa tempo astrologicamente certo". (VON FrANZ, 1993, p. 32).

Interessa ressaltar que para Ficino a magia alquímica aplica-se não apenas aos metais, mas também ao homem. Com essa concepção inaugurou uma nova astrologia, "e às vezes se supõe erroneamente que ele foi um opositor da 
astrologia por causa de suas cartas e escritos mais ou menos virulentos contra seus colegas astrólogos”. (GREENE, 1985, p.119-120). Na verdade ele achava que a astrologia, aplicada como prognosticadora do destino, estava sendo aviltada. Segundo ponderava, a função da astrologia deveria ser outra. Se para os astrólogos medievais um mau trânsito significava um golpe do destino, para ele deveria ser visto como Kairós, o momento apropriado para se estabelecer uma nova relação com o destino através da magia natural.

Eis aí a Moira desafiada de uma forma como nunca tinha sido antes. Para a mente pagã, "teria sido a pior espécie de hybris." (GREENE, p. 120). Para Ficino, Hermes estava revelando, no Asclépio, que o homem é um magnum miraculum, criatura digna de adoração e de honra, pois partilha da natureza de Deus como se ele próprio fosse Deus. Esse fato lhe outorgava o direito de mexer no cosmo, pois participava tanto da natureza de Deus quanto da Moira. O homem já não é mais receptáculo das forças do destino, nem um ser inferior contaminado pelo Pecado Original, e nem será mais levado a fugir da carne através da redenção pelo espírito. Cocriador do cosmo, é agora capaz de reunificar Deus e Moira, espírito e corpo, para que não mais se dividam em dois. Fim do dualismo. De platônico que era, Ficino tornou-se hermético. Com isso conseguiu não ofender nem a Moira, nem a Igreja, nem a astrologia, embora não tivesse sido essa a sua intenção.

A chave para realizar o trabalho de unificar corpo e espírito era a 'imaginação', a transformação da natureza do homem através do intercâmbio com o mundo das imagens, o qual tinha o poder de alterar os efeitos do destino planetário no plano físico (os planetas não são apenas corpos físicos no espaço e nem apenas metais no interior da própria terra, mas também imagens dentro do mundo psíquico do homem). Esse intercâmbio, contudo, deveria ocorrer no momento astrologicamente propício - o Kairós $^{8}$.

Uma incursão sobre a idéia de Destino no Renascimento não poderia desconhecer o pensamento de Maquiavel sobre o assunto. Em um texto citado por Janine - uma carta de 1505 a Soderini - Maquiavel usa uma linguagem astrológica para exprimir seu pensamento. Se cada um fosse sábio, diz

\footnotetext{
8 ) Eugénio Garin, em seu O Zodíaco da Vida, insere este tema na polêmica envolvendo os representantes da magia natural hermética (Marsilio Ficino, Cornelius Agripa e Pietro Pomponazzi), a magia cabalística (Pico della Mirandola) e os humanistas (Petrarca). Foge ao nosso escopo entrar em detalhes sobre esta polêmica extremamente complexa, que se desenvolve em meio a inúmeras contradições e equívocos de toda ordem, sem que seja possível delimitar fronteiras precisas entre visões de mundo aparentemente opostas e contrastantes.
} 
Maquiavel, para "acomodar-se aos tempos e à ordem das coisas", conforme o que se pedisse dele - prudência ou audácia -, a "idéia de que o homem sábio teria o poder de governar as estrelas e o destino se converteria genuinamente em "realidade.' " Aqui, diz Janine, Maquiavel retoma o velho adágio "o sábio dominará as estrelas" (vir sapiens dominabitur astra), que designa o momento operativo do trabalho astrológico. Ou seja, pela metáfora astrológica, insinua a possibilidade de o homem adequar sua natureza aos tempos. (1993, p. 30-33).

A astrologia, diz Janine, pode permitir uma melhor compreensão da fortuna: além de ser o terreno de eleição dessa idéia, é uma "forma de pensamento das mais influentes na passagem do Medievo para a Renascença. [...] Ora, na medida em que permita prever os acontecimentos da roda da fortuna", esta deixa de ser imprevista. "Neste caso, pois, se abriria espaço para uma virtù de maior eficácia do que a descrita por Maquiavel, uma que desse conta mais do que a metade dos acontecimentos, abrangendo, quem sabe, tudo o que ocorre." (p. 32)

\section{ONTEM E HOJE: DO DECLÍNIO À EXPANSÃO}

Essa pretensão da astrologia de abarcar todas as situações do real não tinha nada de esotérico nos séculos XVI e XVII: não representava uma doutrina restrita a um grupo fechado. Keith Thomas afirma que, nessa época, "a astrologia fazia parte da imagem que o homem culto tinha do universo e de seu funcionamento [...] era geralmente aceito que os quatro elementos que constituíam a região sublunar - terra, água, fogo e ar - eram mantidos no seu estado de incessante permuta pelos movimentos dos corpos celestiais [...] era assim menos uma disciplina do que uma imagem do mundo aceita por todos. Ela era necessária para o entendimento da fisiologia e, portanto, da medicina. Ensinava a influência das estrelas sobre as plantas e os minerais e, portanto, moldava a botânica e a metalurgia", constituindo " um aspecto essencial da estrutura intelectual em que os homens eram educados.” (p. 238).

Sua difusão, graças à invenção da imprensa, se fazia por meio de um gênero literário particular: os almanaques - os primeiros grandes sucessos mercadológicos da história da imprensa -, que difundiam seus conhecimentos. O prestígio da astrologia declinou na segunda metade do século XVII, quando se separa da astronomia e se cristaliza num sistema isolado.

À morte de Morin de Villefranche, em 1659, professor de matemática do Collège de France e último astrólogo oficial, conjugam-se as ofensivas 
racionalista e católica, que empurram a astrologia para fora da sociedade religiosa e erudita. No século XVIII, desenvolvem-se as sociedades secretas (particularmente a franco-maçonaria e a rosa-cruz) que procuram reabilitar a tradição astrológica erudita. Clandestina, ela passa a ser poderosamente reprimida, principalmente na França.

O romantismo dá nova vida ao ocultismo: a astrologia penetra no mundo dos poetas, "sensíveis às correspondências entre a vida interior e o cosmos, a alma e a natureza.” (Petrossian, 1972, p. 24). No final do século XIX, há um novo renascimento das ciências ocultas. "E, coisa paradoxal, é no século XIX, em que triunfa um conceito racionalista e cientista do mundo, que renasce o espiritismo, o magnetismo, a quiromancia, a astrologia.” (p. 24). No início do século XX a astrologia procura constituir-se como científica, com o auxílio de estatísticas e do cálculo de probabilidades. A partir de 1930, sai das portas fechadas de consultórios para ganhar a grande imprensa. Começa a se desenvolver a astrologia de massa.

Investigado em seus próprios termos, não se pode dizer que esse sistema de conhecimento seja uma superstição que tenha permanecido enquanto sombra da luz da razão que Adorno defende, mas como um pensamento jogado na sombra pelo próprio domínio dessa mesma racionalidade técnica que não lhe permite ser reconhecido como tal. Como um verdadeiro "retorno do recalcado", a astrologia hoje invadiu a imprensa escrita, o rádio, a televisão, a internet, o romance, a literatura e se espalha por inúmeros periódicos especializados. A julgar pela aparência, com certeza ocupa o primeiro lugar no mercado dos produtos adivinhatórios.

Mas, ao lado da astrologia de massa, existe - e sempre existiu - a astrologia erudita que, segundo Philipe Defrance (1972), é hoje inspirada em duas grandes correntes que exprimem suas aspirações contemporâneas: a que deseja elevá-la à dignidade da ciência e a que a considera uma sabedoria que tem em si as verdades perdidas pela ciência. A primeira permanece um sonho: seus postulados são inverificáveis e as conclusões que tira deles são contraditórias. A segunda é a astrologia iniciática, que se caracteriza antes de mais nada por uma procura individual: "não é um saber que se procura possuir" , mas "um trampolim, ascese que conduz à mutação global do saber e do comportamento.” (p. 89). Nessa linha, é significativa a contribuição que C. G. Jung deu à astrologia atual, ao aplicar a noção de sincronicidade às suas 
explicações das artes divinatórias - astrologia, tarô, I Ching. $9 \mathrm{Na}$ prática, é difícil separar essas duas correntes, daí as inúmeras divergências teóricas que opõem os astrólogos e os subdividem em tendências e subtendências. Tomadas em conjunto, as várias explicações são antitéticas: se é sagrada, seu código não pode ser medido estatisticamente, se é simbólica, não pode ser explicada em termos magnéticos. A esse respeito, comenta Olavo de Carvalho:

Por exemplo, alguns definem a astrologia como o estudo das "influências astrais" (entendidas como radiações energéticas), outros como estudo das puras "coincidências sincrônicas"; alguns vêem nos astros as causas de nossos comportamentos, outros como a projeção do nosso psiquismo individual ou coletivo. Como supor que exista alguma unidade numa ciência que define seu objeto de forma tão variada? (1983, p.29-30)

Por sobre essa mobilidade conceitual, perfila-se uma outra apreensão que entende a astrologia como capaz de apresentar uma visão bastante coerente e unitária do mundo. Essa coerência não deve ser buscada em alguma de suas várias tendências, mas em outro lugar: na estrutura mesma de seu pensamento, que permanece inalterável em todas as versões.

\section{O SISTEMA ASTRO-LÓGICO}

Tentemos, de maneira sucinta, apresentar os princípios gerais que caracterizam a estrutura do pensamento astrológico - seu modo interno de organização que define sua própria natureza enquanto forma de conhecimento. Consideramos que não é possível entender as mensagens horoscópicas analisadas por Adorno isolando-as, como ele faz, do sistema de conhecimento em que elas se apóiam.

Sem a pretensão de inseri-la no quadro de suas coordenadas originárias, que faz parte de um corpo vasto de conhecimentos metafísicos, teológicos e cosmológicos, podemos sintetizar o que é essa estrutura do sistema astrológico a partir dos estudos de André Barbault e da representação que Edgar Morin e Phiplipe Defrance fazem dele como um sistema analógico . ${ }^{10}$ Pode-se entender

\footnotetext{
9 Veja-se a esse respeito o prefácio de C.G.Jung ao livro I Ching, o Livro das Mutações, tradução do chinês para o alemão de Richard Wilhelm. São Paulo, Editora Pensamento, 1997. E também o ilustrativo artigo de Renato Janine "Como a astrologia se tornou junguiana" (Folha de São Paulo, Caderno Mais!, 17 de novembro de 1996).

10 Os autores não se preocupam em definir em que sentido usam o termo "analógico". Segundo Olavo de Carvalho, há muitos equívocos sobre o que seja o raciocínio analógico. Muitos autores supõem que se trata de semelhança de formas, enquanto outros, como Gaston Bachelard, supõem que seja uma forma poética de assimilação da realidade que se distingue radicalmente da apreensão lógica. Muitos astrólogos, por sua vez, usam e abusam da famosa "lei da analogia" para justificar sua arte, mas acabam estabelecendo correspondências entre as configurações celestes e os eventos da vida individual de maneira direta e
} 
esse sistema a partir de seus dois postulados básicos que fundamentam e justificam a interpretação das configurações astrais. $O$ primeiro propõe que o microcosmo humano exprime analogicamente o macrocosmo cósmico.

Esta astro-lógica é ainda por cima uma ana-lógica. Move-se não num universo constituído por objetos em sentido físico, mas numa realidade cósmica viva, no seio da qual está englobado o homem. A astrologia não postula uma simples influência dos astros na vida humana [...] supõe que o universo é um microcosmo em relação ao macrocosmo estelar, quer dizer analogicamente ligado a ele. Os símbolos que exprimem os planetas ou o zodíaco não são sinais arbitrários [...] Efetuam a ligação analógica entre o microcosmo humano e o macrocosmo. (MORIN, 1972, p. 191).

A concepção micromacrocósmica é arcaica, "no sentido em que é o primeiro conceito unitário e coerente do universo que emerge no homem, e no sentido em que todo o espírito humano a tem, mais ou menos virtualmente, mais ou menos profundamente, em si." (MORIN, 1972, p. 192). A reciprocidade analógica entre ambos os planos permite rejeitar a idéia de causalidade. Como a define André Barbault, “a astrologia não trata dos corpos celestes, mensuráveis e contáveis na realidade, mas de uma ordem simbólica. Ela é uma linguagem em que o céu é o significante e o indivíduo o significado: a astrologia trata precisamente da união do significado e do significante no plano simbólico. Por isso os astros não determinam o que é o indivíduo, mas exprimem-no." (1975, p. 26). Para essa astrologia simbólica não existe a necessidade mecânica da ação física ou da relação causal, mas o conhecimento das correspondências universais.

Se há essa correspondência micromacrocósmica, o elo que une ambos se estabelece por meio de "modalidades secretas, equivalências sutis, que a astrologia se atribui a missão de desvendar.”(DEFRANCE, 1972, p. 170). É este o segundo postulado da astrologia, e que pode ser expresso, segundo as palavras de Robert Amadou, da seguinte forma: "[ela se baseia na] unidade do cosmos e na interdependência das partes deste vasto conjunto, concebidas e percebidas de modo analógico." (apud BARBAUlT, 1975, p.20) Ou, como diz o próprio André Barbault: "Neste mundo em que existe uma harmonia pré-estabelecida, há um acordo sinfônico que liga os homens e as coisas.” (p. 20). Os dados astronômicos - os movimentos dos planetas, a trajetória do Sol - são sustentáculos materiais concretos dessa visão cosmológica, em que o indivíduo,

achatada, sem as atenuações e mediações que existem entre estes dois planos. De acordo com Carvalho, “o que estabelece uma analogia entre dois entes... é o fato de que emanam de um mesmo princípio, que cada qual representa simbolicamente a seu próprio modo e nível de ser, e que, contendo em si um e outro, é forçosamente superior a ambos". (Olavo de Carvalho, "Questões de Simbolismo Astrológico", p.42-45). Parece-nos ser neste sentido que Morin e Defrance compreendem o que seja analogia. 
fragmento do Todo, obedece às mesmas leis e é perpassado pelas mesmas forças do universo. É disso, comenta ainda Barbault, que Paracelso quer nos convencer:

Compreendam, por fim, que o astro superior e o astro inferior (dentro de cada um) são uma mesma coisa indivisível. É o céu exterior que mostra o caminho para o céu interior [...] O homem possui um céu que lhe é próprio, que é como aquele que existe fora dele e que possui a mesma constelação. É por isso que o homem está submetido ao tempo: não pelo céu exterior, mas pelo céu interior. ${ }^{11}$

Se é a mesma vida que circula no microcosmo e no macrocosmo - "que já não são duas ordens de grandeza", mas "eixos infinitos em redor dos quais se organiza e se decifra o universo inteiro” (DEFRANCE, 1972, p. 171) - existe entre estes dois mundos um sincronismo perfeito, "e é por isso que as coisas se desenvolvem paralelamente na terra e no céu." Ou seja, ambos são manifestações das mesmas energias que circulam no cosmos. "Partindo dessa noção de harmonia entre o indivíduo e o mundo, um e outro podem ser confrontados, comparados a uma hora e em um lugar determinados: o horóscopo não é outra coisa que o algorítimo e a matriz dessa relação.” (p. 22)

"Cartografia do destino", "mapa astral", "tema natal”, "mapa do céu”, o horóscopo (do grego hora + skopein = ver a hora do nascimento) é um levantamento que se faz da situação de vários planetas, a partir de conhecimentos astronômicos, em determinado local, dia e hora. Pode se referir a pessoas, países, eleições políticas, convulsões sociais, acontecimentos singulares, como uma viagem, etc. As "previsões" ou "leituras" são apoiadas na concepção cíclica do tempo - na trajetória dos planetas, que passam por diversos pontos do zodíaco com intervalos regulares. Nesse sentido, vai ao encontro da lei do eterno retorno, do eterno recomeçar.

Cada tema natal tem dez planetas, doze signos (constelações) do zodíaco e doze casas, ou setores. A inter-relação entre esses elementos e a situação dos planetas em relação uns aos outros (os "aspectos" que formam uns com os outros) permite traduzir os símbolos carregados de muitos significados. A interpretação se faz por meio de um esclarecimento recíproco da parte pelo todo e do todo pela parte. A maneira como se dispõem os planetas num tema, sua dispersão no céu zodiacal são outros dentre os numerosos índices que se leva

${ }^{11}$ Ver Henri Hunwald, Paracelse et l'Astrologie médicale., no VIIe. Congrès International d'Astrologie, C.I.A. In: BARBAULT, André. Del Psicoanalisis a la Astrologia. Buenos Aires, Editorial Dédalo, 1975, p. 27. 
em conta na interpretação: "um jogo de construção - jogo de significações de infinitas possibilidades.” (DEFRANCE, 1972, p. 174-175). Segundo informa Siegfried Böhringer (1992, p. 56), o astrólogo tem, à sua disposição, pelo menos, 800 unidades combinatórias, e por isso precisa adotar critérios de seleção e estabelecer prioridades, em geral de um mestre ou de uma escola. O horóscopo, tal como passou a ser divulgado pela imprensa - o horóscopo de jornal, de rádio, de televisão - leva em conta apenas a data do nascimento, ou seja, os signos zodiacais, determinados pela posição do Sol. ${ }^{12}$

“A astrologia é uma prodigiosa máquina de fazer sentido; uma prática significante que não deixa instalar-se nenhum silêncio entre o real e a sua representação, entre as palavras e as coisas." (DEFRANCE, 1972, p. 176). Conciliase com todos os graus de crença ou doutrinas. Sua prática nunca é conclusiva e nenhuma interpretação esgota a sua totalidade de significações. Talvez isso possa explicar um pouco a sua influência, maleabilidade e permanência como um fato cultural nas mais diversas épocas e nos mais diversos grupos sociais. (p.177).

Devemos nos envergonhar dessa "filosofia primitiva"? - pergunta Barbault (1975, p. 22) - e considerá-la apenas como um engodo? Ou devemos tentar ver o que nela há de fundamental, recalcado pela concepção de mundo científicapositivista? Não é esse reprimido, quase subterrâneo, que volta em seus usuários, aparentemente desinteressados nos postulados que fundamentam "esta grande senhora extraordinariamente bela”, como diz André Breton ? (DEFRANCE, 1972, p. 167). Expulsa da consciência, ela ressurge, não necessariamente com tendências fascistas, como sugere Adorno, mas como uma luz intermitente que se acende por ocasião de uma crise, "sempre que a realidade parece se encher subitamente de sinais, de significações, de coincidências.” (Petrossian,1972, p. 153). Parafrasenado Defrance, a astrologia, assim interrogada, interroga o nosso próprio sistema mental e a nossa própria civilização.

Simbolismo e analogia estão, de fato, enraizados no anthropos: grande parte de nossa vida continua a ser regida por eles. O recalcamento feito pela razão foi parcial. Descobrir seu verdadeiro estatuto, avaliar sua importância, a sua influência, viria talvez a modificar a imagem que a "razão" julgou poder dar do homem. (p. 186)

\footnotetext{
${ }^{12}$ A astrologia de massa não pode fornecer um tema natal individual. Para superar esta lacuna e responder à questão do indivíduo singular, procura individualizar ao máximo o horóscopo "diversificando o diagnóstico quase ao extremo, graças ao computador." (Claude Fischler, "A Astrologia de Massa", in: MORIN, Edgar e outros, O Retorno dos Astrólogos, p. 54).
} 


\section{ALGUMAS CONSIDERAÇÕES}

No decorrer dos séculos a astrologia teve, em vários períodos, função social importante e aceitação por muitos indivíduos de alta posição e importância intelectual, mas, em contrapartida, sempre foi também questionada. Há uma longa tradição de questionamentos nesta área. A sua aceitação por círculos influentes viria a mudar apenas no século XVII, quando se nota um declínio de sua influência no meio acadêmico. Seria de se esperar que a motivação de seu declínio no meio acadêmico fosse a revolução científica que se desenrola nesse século. A tese de Ferreira (2005) aponta um outro caminho, uma direção, procurando mostrar, por meio de ampla historiografia da época, que os questionamentos feitos à astrologia nesse período continuaram a ser os tradicionais e não guardavam ligação estreita com as novas descobertas científicas.

Eugénio Garin mostra em seu livro O Zodíaco da Vida - a Polêmica sobre a Astrologia do Século XIV ao Século XVI (1988) que a batalha em que se envolveu a astrologia nesse período é algo bem complexo. Ele afirma:

Astrologia e religião, astrologia e política, astrologia e propaganda, mas também astrologia e medicina, astrologia e ciência: uma filosofia da história, uma concepção das realidades, um naturalismo fatalista, um culto astral - a astrologia era tudo isto, e mais ainda... Exatamente por isso é de refutar, naturalmente, a tese, apresentada verdadeiramente como um lugar-comum, de uma possível nítida separação, na época do Renascimento, entre astronomia e astrologia. (p.43).

Garin observa que o nascimento da astronomia coincide com o renascer da astrologia. Os astrônomos "modernos", Copérnico e Kepler, eram também astrólogos e neles se matizavam temas da nova ciência, do hermetismo e da magia. As duas profissões não se distinguem bem, pelo menos até o século XVII. Newton, por exemplo, dedicou parte de seu tempo ao estudo da astrologia e era um ardoroso pesquisador da alquimia.

É preciso lembrar essa origem da astronomia no interior da astrologia para pôr fim à divisão radical entre o conhecimento científico e o mágico, concedendo verdade a um e falsidade ao outro. Parece ser essa concepção de ciência identificada com a noção de verdade que Adorno encampa ao condenar a astrologia como superstição.

O fosso entre magos e cientistas é estabelecido com a ofensiva racionalista da Academia de Ciência fundada por Colbert em 1666, que proíbe a prática da astrologia, e com o desenvolvimento do método científico que determinou o que é racionalidade e o que é superstição. Um decreto do rei de 1682 proibe a 
publicação de almanaques astrológicos (sem êxito) e em 1676 um edito manda prender os loucos. Tudo o que é contra a razão e se afasta das normas estabelecidas é jogado à margem da sociedade: a loucura, antes sagrada, tornase insensatez, e a astrologia, desconsiderada nos meios cultos, entra para "o universo subterrâneo das ciências ocultas.” (PEtrossian, 1972, p. 23).

De outra parte, essa caracterização da astrologia só pode ser feita a partir de uma perspectiva evolucionista, o que a torna objeto de investigação mais de historiadores. As reflexões sobre o assunto, como aparecem nos estudos tanto de Durkheim quanto de Mauss, descrevem pela primeira vez a astrologia como um sistema classificatório, atribuindo-lhe "um lugar intermediário na escala evolutiva, que teria seu extremo inferior nas sociedades australianas totêmicas e terminaria nas classificações científicas modernas." (Vilhena, 1990, p. 33). Essas observações evidenciam que, por mais que Adorno insista nas imbricações dialéticas entre mito e ciência - o que poderia nos fazer supor que não separa radicalmente ambos - não ultrapassa a concepção evolucionista do mito, à qual liga a astrologia, que desqualifica como superstição. Dessa perspectiva, como entender que no próprio interior do pensamento filosófico se possa encontrar uma outra racionalidade, que não é essa que triunfou e que, por isso mesmo, não está ligada à concepção de razão que ele defende no seu aspecto emancipador?

Nas passagens sobre as ciências que estão surgindo, a química e a astronomia, e sobre seus antepassados, a alquimia e a astrologia, Ferreira mostra documentalmente que as críticas a estas últimas não chegam a ser severas, do ponto de vista estritamente racionalista. Não se trata de considerar essas "ciências", aos olhos do próprio século XVII, como algo horrível do qual precisaríamos nos livrar no novo estágio da ciência.

Pode-se então perguntar: Será que existia na cabeça de algum filósofo, teórico, intelectual do século XVII a idéia de que, com o surgimento de uma nova concepção de mundo, a astrologia torna-se descartável? Nos manuais de astrologia e na literatura sobre história da astrologia e da ciência se diz que no século XVII a astrologia começa a entrar em declínio com o advento da ciência moderna. É isso que está sendo questionado por Ferreira (2005). A busca de uma documentação para saber o que pensam e sabem os homens dessa época e o modo como compreendem as questões que estão em pauta é o principal mérito dessa tese. Ao tecer os fios invisíveis feitos de valores - crenças, símbolos, emoções, idéias religiosas e políticas que percorrem suas vidas e as de seus contemporâneos no debate astrólogico que se deu neste século - procura 
demonstrar que a questão é muito mais complexa e só pode ser entendida no amplo contexto científico, filosófico, cultural e religioso da Inglaterra do século XVII, e não por meio de explicações que buscam um fator único. Com isso acaba também fornecendo farto material para a compreensão, não apenas do problema em questão, mas da sociedade e da cultura desse século.

O mesmo procedimento poderia ser usado para se estudar outros séculos, outros períodos, onde se possa, por exemplo, notar com mais clareza como se forjou essa idéia da astrologia como superstição, ficção, ou fábula grotesca, tão comum nas abordagens evolucionistas que nos legou o século XIX. Esse poderia ser um outro projeto de estudos. A tese de Ferreira fala um pouco disso em várias passagens, como, por exemplo, quando trata das posições de Calvino (p.98), de Gassendi (p.148), e principalmente na sua conclusão, quando confronta posições de trabalhos historiográficos mais recentes, como os de A. Koiré, George Sarton, Lyn Thornike, Patrick Curry e especialmente Keith Thomas. E contrapõe-se àquelas abordagens segundo as quais qualquer coisa vira superstição, desde que somos arrastados pelo progresso da razão.

\section{REFERÊNCIAS}

ADORNO, T. W. The Stars down to earth: the Los Angeles Times astrology column - a study in secondary superstition, In: Soziologische Schriften II. Frankfurt am Main, Surkamp, 1975, p. 11-119.

BARBAUlT, André . Del Psicoanalisis a la Astrologia. Buenos Aires, Editorial Dédalo, 1975, p. 26.

BRUNING, B. De l'astrologia à la grace. In: BRUNIG, B; LAMBERIGTS; VAN HOUTEN, j. (Orgs), Collectanea Augustiniana, Mélanges T. J. van Badel. Leuven: Institut Historique Augustien, 1990. Augustiniana 40-41 (1990-1991), p. 575-643.

BÖHRINGER, Siegrified. Astrologia: cosmo e destino. Trad. Annemarie Höhn. Petrópolis: Vozes, 1992.

BRUN, Jean. O estoicismo. Lisboa: Edições 70, 1986.

CARVAlHO, Olavo de. Questões de Simbolismo Astrológico. Speculum, Ano 1, no. 1, 1983, p.29-30.

CHAUÍ., Marilena. O Mau Encontro. In: NOVAES, Adauto (Org.). In: A Outra Margem do Ocidente. São Paulo, Minc-Funarte/Companhia das Letras, 1999. p. 453-473. (Col Experiência e Destino).

DEFRANCE, Philipe. A astrologia Erudita. In: MORIN, Edgar e outros. O retorno dos Astrólogos: diagnóstico sociológico. Lisboa: Moraes,1972, p.86-94. 
ELIADE, Mircea. História das crenças e das idéias religiosas. Rio de Janeiro: Zahar Editores, 1979. T.II, V.2.

ÉSQUILO. Prometeu Prisioneiro. Tradução de Jaa Torrano e apresentação de José Cavalcante de Souza. São Paulo, Roswita Kempf Editores, 1985.

FERREIRA, Juliana Mesquita Hidalgo. As influências celestes e a Revolução Científica: a astrologia em debate na Inglaterra do século XVII. 394 p. Tese (Doutorado) Programa de Estudos Pós-Graduados em Filosofia, Pontifícia Universidade Católica de São Paulo, São Paulo, 2005.

GARIN, Eugénio. O Zodíaco da Vida: a Polêmica sobre a Astrologia do Século XVI ao Século XVI. Lisboa, Editorial Estampa, 1988.

GREENE, Lyz. A Astrologia do Destino. São Paulo, Editora Cultrix/Pensamento, 1995 .

HESÍODO. Teogonia, A origem dos Deuses. Estudo e tradução de Jaa Torrano. São Paulo, Massao Ohno - Roswitha Kempf Editores, 1981, pp. 97-98.)

JANINE RIBEIRO, Renato. A última razão dos reis. São Paulo, Companhia das Letras, 1993.

KOIRÉ, Alexandre. Místicos, Espirituales y Alquimistas do séc. XVI alemão. Madrid: Akal Ed., 1981.

NEMÉSIO, De nat. Hom. 38, p.277 (=von Arnim, S.V.F.II, fr.625) apud Giovanni Reali, História da Filosofia Antiga. São Paulo: Loyola, 1994. V.III, p.323-4.

PETROSSIAN, Lena. Do Nascimento ao Renascimento da Astrologia. In: MORIN, Edgar e outros. O retorno dos Astrólogos: diagnóstico sociológico. Lisboa: Moraes,1972, p.15-27.

REZENDE, Vani T. Luzes e Estrelas: Adorno e a Astrologia. São Paulo: Associação Editorial Humanitas/FAPESP, 2006.

THOMAS, Keith. Religião e o Declínio da Magia: crenças populares na Inglaterra, séculos XVI e XVII. São Paulo, Companhia das Letras, 1991, p. 237.

TORRELL, Jean-Pierre OP. Iniciação a Santo Tomás de Aquino: sua pessoa e sua obra. São Paulo: Loyola, 1999.

VILHENA, Luis Rodolfo. O Mundo da Astrologia - estudo antropológico. Rio de Janeiro, Jorge Zahar Editor, 1990.

VON FRANZ, Marie-Louise. Alquimia: Introdução ao simbolismo e à Psicologia. São Paulo, Editora Cultrix, 1993.

YATES, Frances A. Giordano Bruno e a tradição hermética. São Paulo: Cultrix, 1995. 